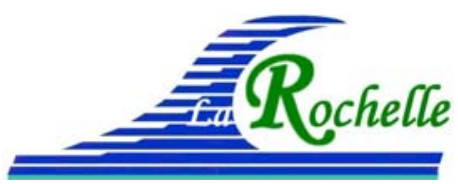

XVèmes Journées Nationales Génie Côtier - Génie Civil

La Rochelle, 29 au 31 mai 2018

DOI:10.5150/jngcgc.2018.037

(c) Editions Paralia CFL

disponible en ligne - http://www.paralia.fr - available online

\title{
Using spaceborne imagery to infer the topography of the intertidal zone: a case study for the shoreline of Chittagong (Bangladesh) using PROBA-V data
}

\author{
Matthias BERGMANN ${ }^{1}$, Fabien DURAND ${ }^{1}$, Yann KRIEN ${ }^{1}$, \\ MD Jamal Uddin KHAN ${ }^{1,2}$, Marufa ISHAQUE ${ }^{1}$, Laurent TESTUT ${ }^{1}$, \\ Stephane CALMANT ${ }^{1}$, Philippe MAISONGRANDE ${ }^{1}$, \\ AKM Saiful ISLAM ${ }^{2}$, Fabrice PAPA ${ }^{1}$, Sylvain OUILLON ${ }^{1}$
}

1. Laboratoire d'Etudes en Géophysique et Océanographie Spatiales (LEGOS), 14 Avenue Edouard Belin, Toulouse, France.

2. Institute of Water and Flood Management (IWFM), Bangladesh University of Engineering and Technology, Bangladesh.

fabien.durand@ird.fr

\begin{abstract}
:
The monitoring of the topography of the intertidal zone is one of the challenging tasks across oceans shoreline. The recognized role of the intertidal topography in the nearshore hydrodynamics motivated the present study. We consider the Chittagong region of the northern Bay of Bengal because of its exposure to powerful cyclonic surges and associated inundation hazard. An original procedure to estimate the topography relying on spaceborne optical imagery is presented here. The procedure is applied to recent PROBA-V multi-spectral imagery mission and a digital elevation model (DEM) is generated covering a stretch of $40 \mathrm{~km}$ shoreline around Chittagong city. After comparing the DEM with in-situ surveys, we conclude that the accuracy is within 1 to 2 $\mathrm{m}$, viz. within the range of the validation dataset. Our procedure is objective and computationally light. Thus it is easy to automate for application to any other imagery satellite, including at high resolution and in real time.
\end{abstract}

Keywords:

Topography, PROBA-V, Intertidal DEM, Bangladesh.

\section{Introduction}

The coastal strip of Bangladesh in the northern Bay of Bengal has a very low elevation, typically lower than $4 \mathrm{~m}$ above mean sea level (MSL) over the most of the Bengal delta (KRIEN et al., 2016), figure 1. The region is characterized by a broad and very shallow shelf and a macro-tidal regime with a tidal range in excess of $6 \mathrm{~m}$. These factors together with the presence of intense cyclonic activity during inter-monsoon season make the shoreline of Bangladesh prone to surge and flooding (ALI, 1996).

State-of-the-art numerical hydrodynamic models fail to accurately reproduce the spatiotemporal evolution of the coastal flooding observed during these extreme events 
(KRIEN et al., 2017). Among the various factors limiting the performances of the numerical models is the improper knowledge of the near-shore bathymetry and land topography. The near-shore region is also prone to morphological changes as a result of erosion and accretion processes acting over a broad range of time scale (from days to decades). The current practice of costly in situ hydrographic surveys is not sustainable for proper monitoring of such a dynamic morphology. Indeed, even small coastal research vessels cost typically around 10000 euros and do not cover more than 20 linear $\mathrm{km}$, per day of operation.

Here we present a novel approach, relying on remote sensing multi-spectral data from the $100 \mathrm{~m}$ resolution of the four channels of the PROBA-V satellite (DIERCKX et al., 2014). We use it to infer the tidally-driven migration of the shoreline and the endproduct of our study is a digital elevation model (DEM) of the intertidal area referenced to MSL.

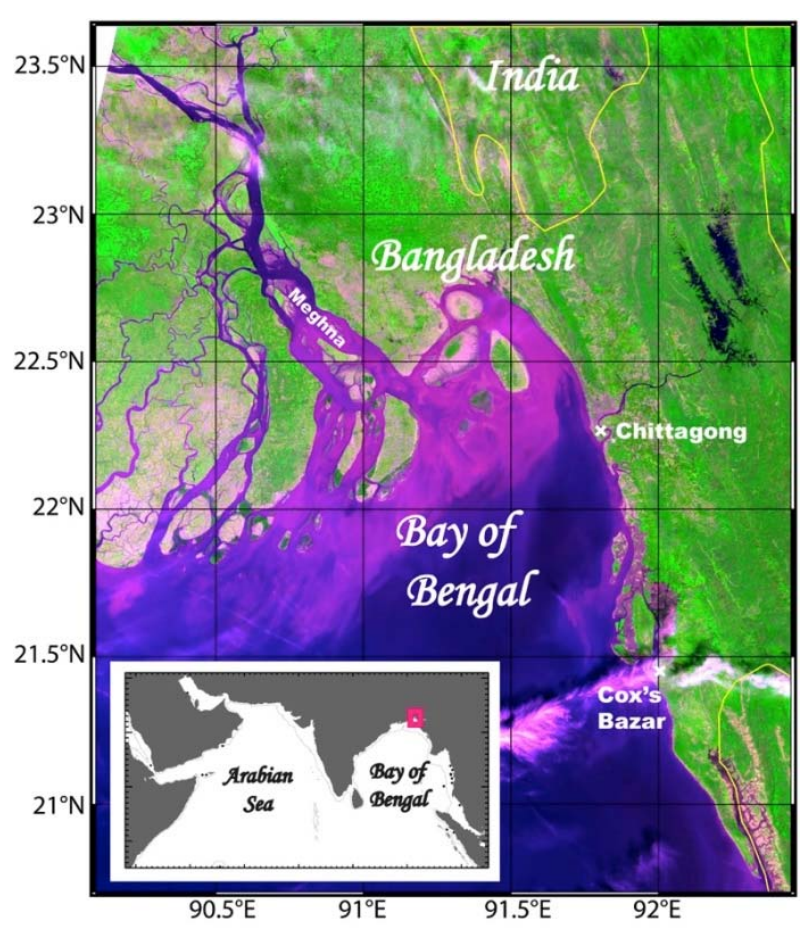

Figure 1. Geography of the study area.

The background is a quasi-true-colour synthesis from PROBA-V data on 11/03/2014.

\section{Dataset and Methodology}

\subsection{Pre-processing of the dataset}

We consider the 5-day syntheses of multi-spectral radiometric data of VEGETATION instrument onboard PROBA-V (DIERCKX et al., 2014). These data are available free of cost on http://www.vito-eodata.be/PDF/portal/. Four spectral channels - blue 


\section{XVèmes Journées Nationales Génie Côtier - Génie Civil \\ La Rochelle, 29 au 31 mai 2018}

(447-493 nm), red (610-690 nm), near-infrared (NIR, 777-893 nm) and short-wave infrared (SWIR, 1570-1650nm), at $100 \mathrm{~m}$ resolution are used (figure 2, a-d). All the files are already orthorectified, georeferenced and corrected for optical and sensor errors, atmospheric effects, atmospheric effects and cosmic rays. From three years of data, between March 2014 and May 2017, a subset of 16 images was handpicked based on cloud cover and sufficiency to cover the full tidal cycle ranging from high tide to low tide.

Our approach essentially builds on the procedure of BERTELS et al. (2016), except that we considered the highest resolution $(100 \mathrm{~m})$ PROBA-V syntheses (while they considered the $1 \mathrm{~km}$ and $333 \mathrm{~m}$ products only). We normalized the individual channels and then converted the resulting data into a synthetic red-green-blue (RGB) space to take advantage of the land/sea contrast captured in the SWIR channel, as in equation 1 (the subscript "norm" means the channel is normalized by its maximum value).

$$
\begin{aligned}
& \text { red }_{\text {new }}=\left(1-S W I R_{\text {norm }}\right)+\left(S W I R_{\text {norm }} \times \text { red }_{\text {norm }}\right) \\
& \text { green }_{\text {new }}=\left(1-S W I R_{\text {nrom }}\right)+\left(S W I R_{\text {norm }} \times N I R_{\text {norm }}\right) \\
& \text { blue }_{\text {new }}=\left(1-S W I R_{\text {norm }}\right)+\left(S W I R_{\text {norm }} \times \text { blue }_{\text {norm }}\right)
\end{aligned}
$$
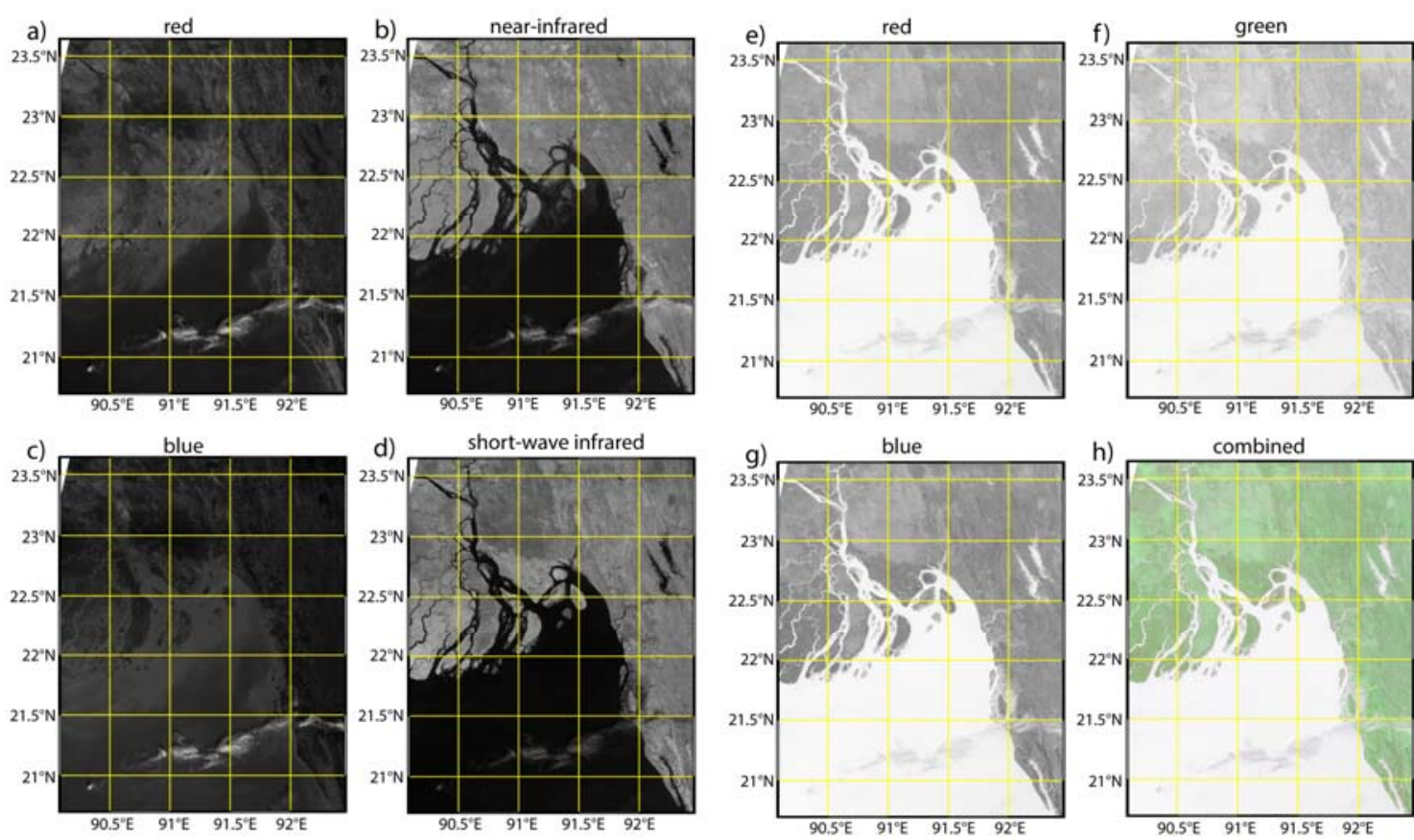

Figure 2. Example of PROBA-V 5-day synthesis at $100 \mathrm{~m}$ resolution over our area for original colour space $(a-d)$ and for colour space defined by equation (1) $(e-h)$ (on 11/3/2014).

This conversion can be interpreted as a red, green, blue and alpha (RBGa) to RBG conversion where the image is overlayed over a white background (figure 2, e-h). Here 


\section{Thème 3 - Instrumentation, mesures, imagerie et télédétection}

the SWIR channel is used as the alpha channel, as in SWIR water surfaces have a very low intensity (figure 2d), resulting in very high transparency. Blending the RGBa composition with a white background results in water areas becoming nearly white; while the brightness of land surfaces (showing high intensity in SWIR channel) remains practically unaffected. We considered the SWIR channel preferably to the NIR channel because the SWIR appears least affected by the sediments outflow seen in the northernmost part of Bay of Bengal, close to the mouth of the Meghna River (figure 2). In NIR, the land/water contrast is not as prominent there. The red and blue channels are included in the conversion because their resolution is higher than the NIR and SWIR channels in the native radiometric measurements of PROBA-V. The data of the NIR and SWIR channels are upscaled by PROBA-V pipeline so that their resolution matches the resolution of the red and blue channels data. This ensures that the smaller structures are retained in the composition, which would otherwise be blurry due to the upscaling of the NIR and SWIR channels. In the resulting synthetic RGB composition (figure $2 \mathrm{~h}$ ), water areas appear extremely bright, which will favour the identification of the shoreline.

\subsection{Shoreline extraction}

The basic principle of our shoreline detection procedure is to identify the border between water and land areas, which will be done by a thresholding approach. To determine the threshold, the synthetic RGB composition is converted into hue, saturation and value (HSV) colour space (PEKEL et al., 2014), figure 3. In the rest of our study, only the hue and value channels will be considered. The rationale for designing our shoreline detection algorithm in the HSV space rather than in the RGB space is that hue is particularly sensitive to land cover change: typically a pixel covered with water at high tide, and becoming dry at low tide (PEKEL et al. 2014). The switching also results in contrast normalization allowing same algorithm set-up to process various scenes with different illumination conditions. From the distribution of our dataset in the hue-value domain it is seen that two populations (blue vs. red) are well separated, with points located in the offshore part of the ocean (in blue) restricted to low hue (below $180^{\circ}$ ) / high value (above 0.8 ), whereas remaining points (in red) are mainly restricted to the higher part of the hue domain only (above $200^{\circ}$ ), figure $4 \mathrm{a}$. This clear separation allows us to convert our maps of hue and value to binary images, as follows. First, a gross, conservative, ocean mask is pre-defined once and for all by manual selection covering the offshore ocean only. On the masked domain (for value channel) and on the inversely-masked domain (for hue channel), we compute the median value and the standard deviation. These quantities are used as the thresholds to generate binary images identifying the water pixels according to equation 2 and 3 for hue and value respectively. 


\section{XVèmes Journées Nationales Génie Côtier - Génie Civil \\ La Rochelle, 29 au 31 mai 2018}

$$
\begin{aligned}
& \operatorname{IsWater}_{\text {hue }}(i, j)=\neg\left(\left(I_{\text {hue }}(i, j)<T_{\text {hue }}+n_{\text {hue }} \cdot \sigma_{\text {hue }}\right) \wedge\left(I_{\text {hue }}(i, j)<T_{\text {hue }}-n_{\text {hue }} \cdot \sigma_{\text {hue }}\right)\right) \\
& \operatorname{IsWater~}_{\text {value }}(i, j)=\left(I_{\text {value }}(i, j)<T_{\text {value }}+n_{\text {value }} \cdot \sigma_{\text {value }}\right) \wedge\left(I_{\text {value }}(i, j)<T_{\text {value }}-n_{\text {value }} \cdot \sigma_{\text {value }}\right)
\end{aligned}
$$

with $I_{\text {hue }}$ and $I_{\text {value }}$ being the masked hue and value channels, IsWater $r_{\text {hue }}$ and IsWater $r_{\text {value }}$ being the resulting binary images, $T$ and $\sigma$ being the thresholds (median) and standard deviations, and $n$ being the scaling factor of the standard deviation. The higher the scaling factor, the less strict is the thresholding. The scaling factors are kept constant for all images. In our case, after several trials, we fixed the factor to be 0.4 and 5.0 for hue and value respectively. These images are then AND-corrected with the gross ocean mask. As this image can contain some small-scale noise, all blobs with a size of less than 500 pixels are removed, as well as all holes with a size of less than 50 pixels.
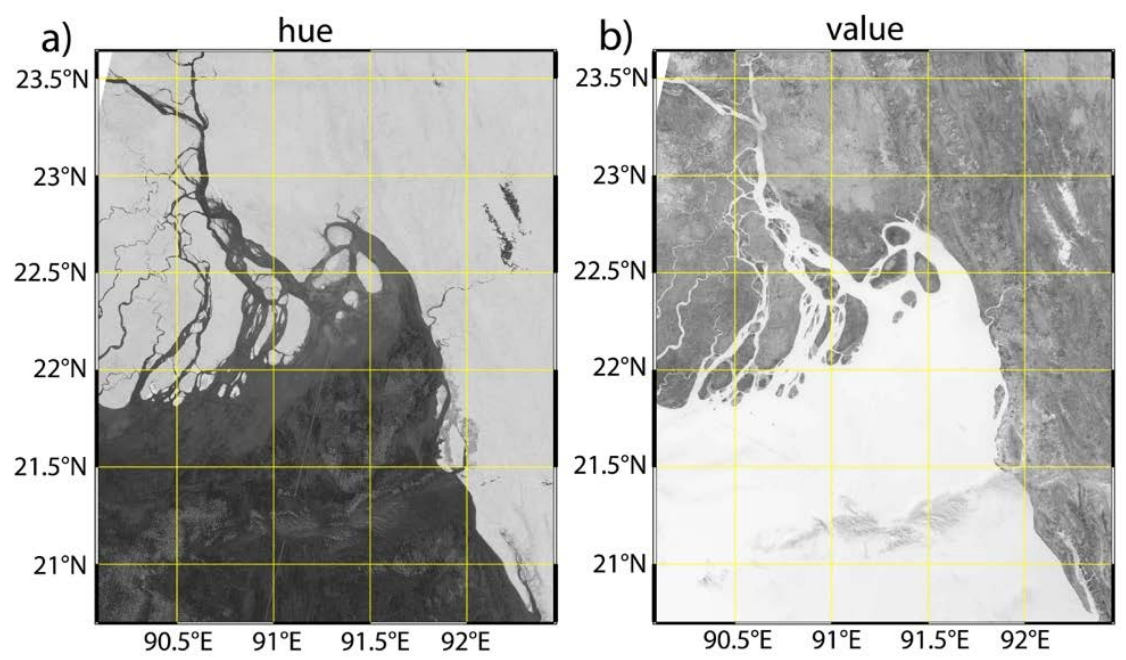

Figure 3. Same as figure 2, for the HSV synthetic colour space: (a) hue channel, (b) value channel. The grey scale for hue and value vary from 0 (white) to 1 (black).

The final step, the identification of shoreline from this clean map, is done by convolution of the image with a Laplacian kernel, figure $4 \mathrm{~b}$. We applied the procedure routinely to all 16 images of our dataset and derived 16 different shoreline maps, each one corresponding to a different sea surface height of the tidal cycle. It is clearly seen that the shoreline moves landward during rising tide and seaward during ebb tide, figure $5 \mathrm{a}$. The width of the intertidal area reaches its maximum at $22.3^{\circ} \mathrm{N}$, with about $1500 \mathrm{~m}$. This legitimates a posteriori the choice of our region, keeping in mind the $100 \mathrm{~m}$ resolution of our PROBA-V dataset.

\subsection{Vertical Referencing of the DEM}

We have used the water level records from a tidal model to infer the vertical referencing of the horizontal shorelines estimated in the previous section. To our knowledge, the most realistic tidal model published over the region is that of KRIEN et al. (2016). 


\section{Thème 3 - Instrumentation, mesures, imagerie et télédétection}

From the model, an elevation is assigned to each pixel of our batch of detected PROBA$\mathrm{V}$ shorelines, based on the time stamp provided with the images (at one minute accuracy) and the modelled sea level height.

a)

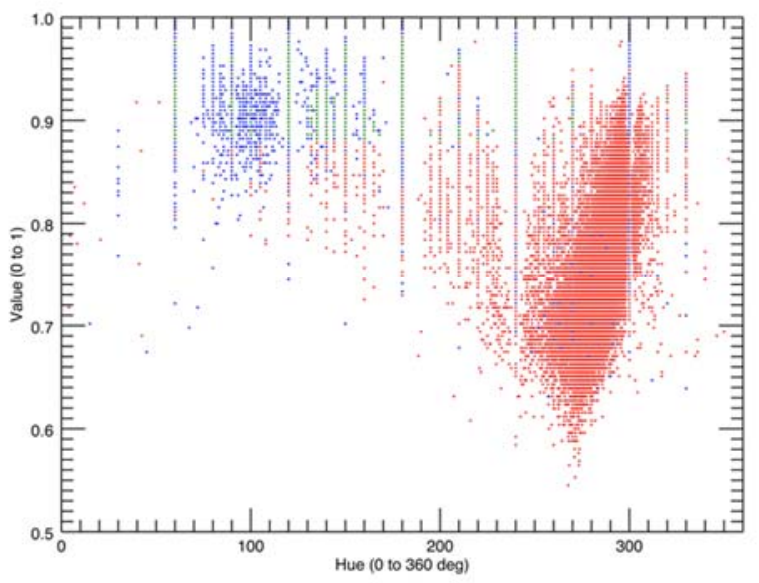

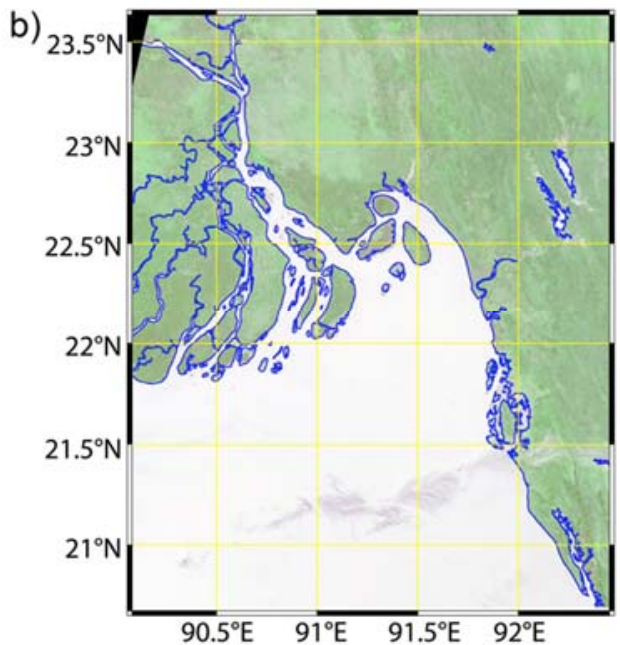

Figure 4. (a) Scatter plot of the hue and value channels obtained in PROBA-V dataset (restricted to three dates among those we considered, and plotting only one point every other 50, for clarity). Blue points fall within our ocean mask; red points fall out of it.

Green points are the shoreline pixels subsequently identified by our algorithm. (b)

Shoreline (blue) obtained at the end of our detection procedure, for the example of $11 / 3 / 2014$. For visual purpose and clarity, note that the shoreline width was artificially increased to 9 pixels.

\section{Results}

\subsection{Intertidal DEM}

The DEM we obtain from the vertical referencing of our batch of PROBA-V shorelines over Chittagong area covers the major part of the tidal heights, with elevations ranging from $-2.25 \mathrm{~m}$ to $+2.25 \mathrm{~m}$, figure $5 \mathrm{a}$. Indeed, the observed tidal range is $+/-2.5 \mathrm{~m}$ in Chittagong. In some instances, different contour lines appear to overlap. The reason for this is the similar tidal conditions sampled by our PROBA-V dataset on different dates. Of course, this effect is more likely to occur where the terrain slope is steepest (as it is around $22.25^{\circ} \mathrm{N}$ for instance). Keeping in mind the resolution of our PROBA-V dataset, as well as the typical resolution of state-of-the-art hydrodynamical models used to simulate the coastal dynamics over our area (of order $100 \mathrm{~m}$ or coarser), we decided to retain only three contour lines in our DEM for the subsequent analyses (viz. the highest, the lowest, as well as the one closest to the mean sea level, at each latitude of our domain). 


\section{XVèmes Journées Nationales Génie Côtier - Génie Civil \\ La Rochelle, 29 au 31 mai 2018}

\subsection{Validation of our DEM against in-situ soundings}

This validation relies on sounding points digitized from two nautical charts from Bangladesh Navy Hydrographic and Oceanographic Centre covering our region of interest (chart \#3001 and chart \#3509). We could find 30 comparison points in the intertidal area (figure 5b). The two datasets present some significant differences, with a prominent shallow bias of our DEM compared to the soundings (mean $1.2 \mathrm{~m}$, standard difference $1.5 \mathrm{~m}$ ), figure $5 \mathrm{c}$. These values are commensurate with the commonly accepted accuracy of in situ soundings (estimated to 1-2 m), (SCIORTINO, 2010). This comparison gives strong confidence in our product and allows us to also conclude to an intrinsic accuracy of our DEM in the order of 1-2 $\mathrm{m}$ as well.
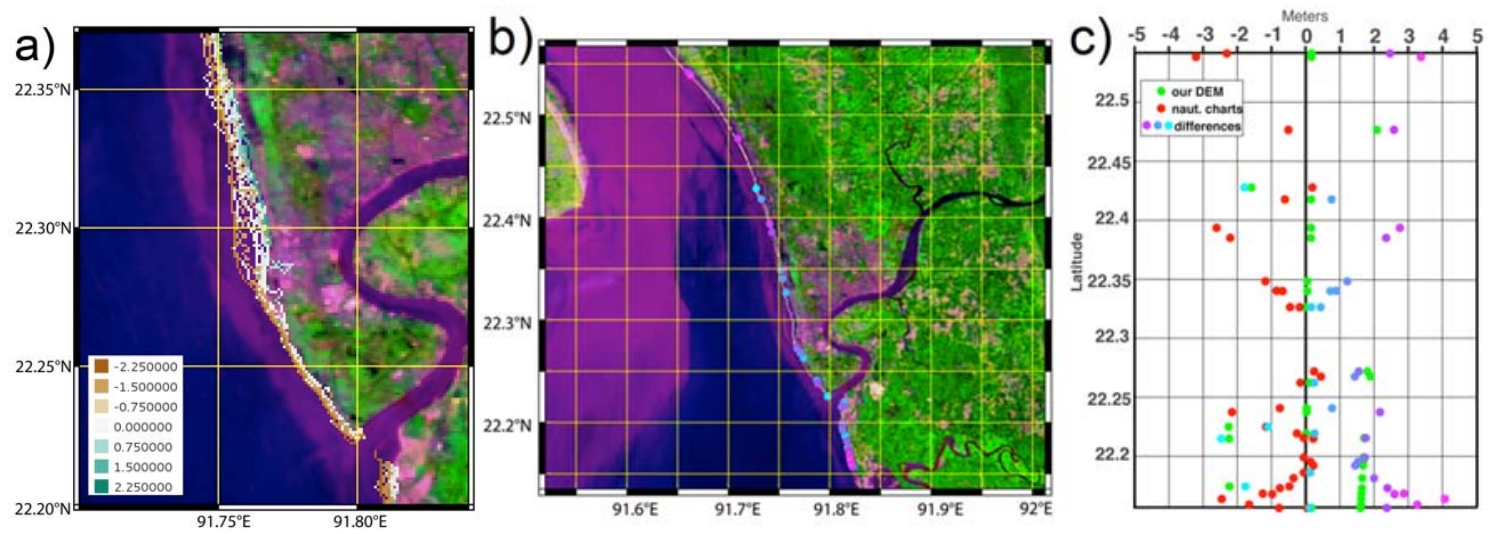

Figure 5. (a) Structure of our DEM over Chittagong area. Elevations are referenced to mean sea level (in m). Positive upwards. (b) Positions of the in situ sounding points superimposed (bullets). The bullets colours (pink-purple-blue) correspond to the magnitude of the difference between our DEM and the in situ soundings bathymetry. (c) Latitude-height plot of our DEM (green), of the in situ soundings (red), and of their difference (pink-purple-blue) (positive upwards).

\section{Conclusions}

Just like in many other parts of the world ocean coastline, the hydrodynamics and geodesy scientific community of the rim of the Bay of Bengal has been suffering from a lack of knowledge on the topography of the near-shore region. This lack of information has been hampering our understanding and our capability to predict some fundamental natural processes such as the oceanic tide or the cyclonic storm surges and the associated coastal flooding events.

Here we present a procedure designed to provide an accurate estimate of the topography of the intertidal zone, based on the combination of spaceborne imagery and a tide model. In essence, our methodology amounts to an original procedure of water line detection. We apply this method to the multi-spectral radiometric data of the 
VEGETATION instrument on-board PROBA-V. With a comparison against in situ charts, we could conclude to an accuracy of our DEM in the order of 1-2 m over our area. The distinct advantage of our method lies in its automated processing: the algorithm has to be tuned once and for all for a given sensor and can be then applied routinely to the whole satellite archive without the need to calibrate it sample-bysample. Our approach is computationally light and suited to upcoming generations of higher resolution radiometric sensors. It also has promising potential for real-time monitoring of the shoreline morphology, in regions subject to erosion/accretion processes.

\section{References}

ALI A. (1996). Vulnerability of Bangladesh to climate change and sea level rise through tropical cyclones and storm surges. Water, Air, and Soil Pollution, Vol. 92, pp 171-179. https://doi.org/10.1007/BF00175563

BERTELS L., SMETS B., WOLFS D. (2016). Dynamic water surface detection algorithm applied on PROBA-V multispectral data. Remote Sensing, Vol. 8(12). doi:10.3390/rs 8121010

DIERCKX W., STERCKX S., BENHADJ I., LIVENS S., DUHOUX G., VAN ACHTEREN T., FRANCOIS M., MELLAB K., SAINT G. (2014). PROBA-V mission for global vegetation monitoring: standard products and image quality. International Journal of Remote Sensing, Vol. 35(7), pp 2589-2614. https://doi.org/10.1080/01431161.2014.883097

KRIEN Y., MAYET C., TESTUT L., DURAND F., TAZKIA A. R., ISLAM A. K. M. S., GOPALAKRISHNA V. V., BECKER M., CALMANT S., SHUM C. K., KHAN Z. H., PAPA F., BALLU V. (2016). Improved bathymetric dataset and tidal model for the northern Bay of Bengal. Marine Geodesy, Vol. 39(6), pp 422-438. https://doi.org/10.1080/01490419.2016.1227405

KRIEN Y., TESTUT L., ISLAM A. K. M. S., BERTIN X., DURAND F., MAYET C., TAZKIA A. R., BECKER M., CALMANT S., PAPA F., BALLU V., SHUM C. K., KHAN Z.H. (2017). Towards improved storm surge models in the northern Bay of Bengal. Continental Shelf Res., Vol. 135, pp 58-73. https://doi.org/10.1016/j.csr.2017.01.014

PEKEL J.-F., VANCUTSEM C., BASTIN L., CLERICI M., VANBOGAERT E., BARTHOLOMÉ E., DEFOURNY P. (2014). A near real-time water surface detection method based on HSV transformation of MODIS multi-spectral time series data. Remote Sensing of Environment, Vol. 140, pp 704-716. https://doi.org/10.1016/j.rse.2013.10.008 SCIORTINO J.A. (2010). Fishing harbour planning, construction and management. Fisheries and Aquaculture Technical Paper. No. 539. Food and Agriculture Organization of the United Nations, Rome, 337 p. 